\title{
Effects of COVID-19 Infection on P-Wave Dispersion, P-Wave Peak Time and Atrial Conduction Times
}

\section{B Bedrettin Boyraz1, ๑ Ersin İbişoğlu²}

\author{
1Tatvan State Hospital, Clinic of Cardiology, Bitlis, Turkey \\ 2̇̇stanbul Başakşehir Çam and Sakura City Hospital, Clinic of Cardiology, İstanbul, Turkey
}

\begin{abstract}
Objectives: The relationship between atrial conduction times and paroxysmal atrial fibrillation has been demonstrated in some studies. There have been case reports showing that coronavirus disease-2019 (COVID-19) infection caused arrhythmic cases including atrial fibrillation. We investigate the effect of different clinical presentations of COVID-19 infection on these parameters in this study.

Materials and Methods: We divided the patients who were infected by COVID-19 into three groups according to computerized tomography and real-time polymerase chain reaction test results. The longest P-wave duration, shortest P-wave durations, P-wave dispersion and P-wave peak duration were calculated in the surface electrocardiography of these patients.

Results: Patients with both real-time polymerase chain reaction test positive and pneumonia had the highest P-wave maximum duration $(113.08 \pm 9.671 \mathrm{~ms}$ vs $102.44 \pm 7.412 \mathrm{~ms}$. and $99.18 \pm 9.292 \mathrm{~ms} ; \mathrm{p}=0.000)$ and the highest P-wave dispersion $(53.34 \pm 7.705 \mathrm{~ms}$ vs $40.58 \pm 4.813 \mathrm{~ms}$. and $35.42 \pm 4.116 \mathrm{~ms} ; \mathrm{p}=0.000)$ and the longest $\mathrm{P}$-wave peak time ( $56.79 \pm 7.767 \mathrm{~ms}$ vs $51.92 \mathrm{~ms} \pm 6.443 \mathrm{~ms}$ and $50.55 \pm 11.63 \mathrm{~ms} ; \mathrm{p}=0.008)$. P-wave dispersion was found longer in patients with real-time polymerase chain reaction test only compared to patients with only pneumonia $(40.58 \pm 4.813 \mathrm{~ms}$. vs $35.42 \pm 4.116 \mathrm{~ms} ; \mathrm{p}=0.000$ ).

Conclusion: Patients with COVID-19 pneumonia with real-time polymerase chain reaction test positivity have longest P-wave dispersion, P-wave maximum duration and P-wave peak duration. It seems that they have a risk of paroxysmal atrial fibrillation. That's why, that group may benefit most from strict electrocardiography follow-up.
\end{abstract}

Keywords: COVID-19, p-wave dispersion, electrocardiography, atrial fibrillation

Address for Correspondence: Bedrettin Boyraz, Tatvan State Hospital, Clinic of Cardiology, Bitlis, Turkey

e-mail: bedrettinboyraz@yahoo.com ORCID: orcid.org/0000-0003-1831-182X

Received: 13.05.2021 Accepted: 19.08.2021

Cite this article as: Boyraz B, İbişoğlu E. Effects of COVID-19 Infection on P-wave Dispersion, P-wave Peak Time and Atrial Conduction Times. EJCM 2021;9(3):143-149.

DOI: 10.32596/ejcm.galenos.2021-05-033 


\section{Introduction}

Coronavirus disease-2019 (COVID-19) infection has become a pandemic by show up in Wuhan city of China and has been spreading all over the world. More than eight million people were infected by the virus, and it caused more than 400,000 deaths by June $18^{\text {th }}, 2020^{(1)}$. Although the infectious agent has been previously known, effects of this novel kind of virus on humans have not been clearly demonstrated. The dark parts in the pathogenesis protect its secret. While initially thought to be progressing only with pneumonia, case reports have emerged that it causes myocarditis, arrhythmia problems, coagulopathy, and micro-embolism ${ }^{(2-5)}$. Drugs with proarrhythmic effects are frequently used in the treatment of COVID-19 infection in our country and in the world ${ }^{(6-8)}$. In our country, anticoagulant therapy has been added to patients in accordance with the national guidelines ${ }^{(8)}$. Anticoagulant therapy is thought to reduce the mortality and morbidity of patients ${ }^{(8-10)}$. This suggests that the possible procoagulant or arrhythmic condition affects patients.

Real-time polymerase chain reaction (rt-PCR) and chest computerized tomography (CT) are used in the diagnosis of COVID-19 disease. The rt-PCR test is seen as the most widely used and most reliable method. However, the sensitivity of rt-PCR test can vary depending on the stage of patients' disease and the appropriateness of the sampling. CT is widely used, too. However, radiological imaging may have difficulty in clearly distinguishing other viral and atypical pneumonias. In our hospital, we apply both CT and rt-PCR tests to the patients in accordance with the national guidelines ${ }^{(8)}$.

Atrial fibrillation is a frequent pathological arrhythmia among elderly people and patients who have comorbid chronic illnesses. It is one of the most common causes of thromboembolism. Some diseases or conditions have been shown to trigger paroxysmal atrial fibrillation. Infectious diseases are the leading causes ${ }^{(11)}$. It has been shown in some case reports that patients with COVID-19 infection have atrial and ventricular tachyarrhythmias ${ }^{(12,13)}$. It has shown that COVID-19 infection causes myocarditis ${ }^{(14)}$.
The values of the longest $\mathrm{P}$-wave duration (P-max), $\mathrm{P}$-wave dispersion (PwD) and $\mathrm{P}$-wave peak duration (PwPD) in demonstrating the function of the atrial conduction system and showing the risk of paroxysmal atrial fibrillation have been demonstrated in many studies $^{(15-18)}$.

In this study, we evaluated these parameters by dividing patients into groups with the most common clinical presentations of known COVID-19 infection in patients. As a result, we aimed to show which patients among these groups may have the highest P-max, PwD, and PwPD. Based on this, we wanted to estimate which group of patients might have a higher risk rate of paroxysmal atrial fibrillation. In addition, we wanted to show the effects of COVID-19 infection on the atrial conduction tissue in cases with pneumonia and in cases without pneumonia.

\section{Materials and Methods}

All procedures performed in studies involving human participants were in accordance with the ethical standards of institutional and/or national research committee and with the 1964 Helsinki Declaration and its later amendments or comparable ethical standards. Permission for the research was taken from Republic of Turkey Ministry of Health. Permission number is 2020-05-20T17 56 41. Ethical approval was taken from University of Health Sciences Turkey, Diyarbakır Gazi Yaşargil Training and Research Hospital Ethics Committee, with the report number of 509.

\section{Patient selection}

Patients who applied to Tatvan State Hospital between the ages of 15 and 90 years were included in the study. Patients who applied to the hospital with COVID-19 infection were divided into three groups according to their diagnostic status. In determining these groups, the decision was made according to the results of CT and rt-PCR tests. Due to the false negative results, patients with two negative PCR results were considered negative. Possible wrong results were tried to be minimized in this 
way. In the CT evaluation, the results were based on the reports made by radiologists, compatible with COVID-19 pneumonia according to national and international guidelines. Patients whose CTs were compatible with COVID-19 pneumonia and positive rt-PCR tests were included in group 1. Patients in group 2 were composed of patients who did not suffer from pneumonia but the performed rt-PCR tests were COVID-19 positive. Patients in group 3 were composed of those whose CT results were compatible with COVID-19 pneumonia but had negative rt-PCR tests.

Demographic data of patients, including their age, gender, comorbid vascular, cardiac, renal, pulmonary, and diabetes diseases were noted. The results of the Hemoglobin ( $\mathrm{Hb}$ ), White Blood Cells (WBC), Platelet (Plt), Urea, Creatine, Alanine aminotransferase (ALT), Aspartate aminotransferase (AST), C-Reactive Protein (CRP) and Troponin tests of the patients which had been examined prior to any treatment were recorded.

\section{Electrocardiographic Parameters}

Twelve lead electrocardiograms (ECGs) were obtained with $10 \mathrm{~mm} / \mathrm{mV}$ amplitude and $25 \mathrm{~mm} / \mathrm{s}$ rate with standard lead positions in a supine position. ECGs were manually measured before PCR test results. Heart rate PR interval time and QRS interval duration were calculated and noted. The duration measurements of the P-wave were determined as the duration from the beginning of the $\mathrm{P}$-wave to the end of the $\mathrm{P}$-wave and the duration from the beginning of the P-wave to the end of P-wave on the leads with the longest (P-max) and shortest (P-min) $\mathrm{P}$-wave. PwD was calculated by finding the difference between P-max duration and P-min duration. The time from the start of the P-wave to the peak of the P-wave was calculated and PwPD was found.

\section{Statistical Analysis}

Values are expressed as the mean \pm standard deviation (SD). Categorical data were compared using $\chi^{2}$ analysis and Fischer exact test. SPSS-23 Statical analysis software IBM was used for statistical analysis. Normality of the variables was tested with the Kolmogorov-Smirnov method. Comparison among the three groups was performed using a one-way analysis of variance (ANOVA). The Levene's statistic test was performed in the evaluation of variance homogeneity. The Scheffe test was used in variance homogeneous parameters, Tamhane and Games-Howell test in non-homogeneous parameters. The Kruskal-Wallis test was used for variables that did not show normal distribution. The Mann-Whitney U test was used for the parameters in which difference was detected on the Kruskal-Wallis test. Statistically significant p-value was considered as 0.05 .

\section{Results}

\section{Demographic Information}

There were 38 patients in the first group, 36 patients in the second group and 33 patients in the third group. The average age of the patients was $49.3 \pm 15.5$ years in group $1,38.5 \pm 16.4$ years in group 2 , and $42.6 \pm 18.4$ in group 3 . While there was no significant difference between group1 and group 3 and between group 2 and group 3, there was a significant difference between group 1 and group 2 $(p<0.05)$. There was no significant difference between the groups in terms of coronary artery disease (CAD), chronic renal failure (CRF), diabetes mellitus, hypertension, heart failure and chronic obstructive pulmonary diseases. The demographic characteristics of the study subjects were summarized in Table 1.

\section{Laboratory and Biochemistry Tests Results}

There was not significant difference between the groups in terms of $\mathrm{Hb}$, Plt, urea, creatin, ALT, AST and troponin levels. WBC values were significantly higher in group 3 than in group $2(\mathrm{p}<0.05)$ and higher than group $1(\mathrm{p}<0.05)$. However, WBC values were not significant between group 1 and 2. CRP levels were significantly lower in group 2 than in group 1 and group $3(\mathrm{p}<0.05)$ but there was no significant difference between group 1 and 3 in the levels of CRP. The results of laboratory and biochemistry tests are summarized in Table 2 . 


\section{Electrocardiographic Parameters}

There was not significant difference between patients' heart rates, PR interval durations, and QRS interval durations. P-max durations were significantly higher in group 1 than in group 2 and group 3 (113.08 \pm 9.671 ms vs $102.44 \pm 7.412 \mathrm{~ms}$ vs $99.18 \pm 9.292 \mathrm{~ms} ; \mathrm{p}=0.000$ ), and there was no significant difference between group 2 and group $3(\mathrm{p}=0.120)$ (Figure 1). The durations of

Table 1. Demographic characteristics of patients

\begin{tabular}{|c|c|c|c|c|}
\hline & $\begin{array}{l}\text { Group } 1 \\
\text { (Both CT and rt-PCR } \\
\text { results compatible } \\
\text { with COVID-19) }\end{array}$ & $\begin{array}{l}\text { Group } 2 \\
\text { (rt-PCR tests } \\
\text { compatible with } \\
\text { COVID-19, but CT is } \\
\text { not compatible) }\end{array}$ & $\begin{array}{l}\text { Group } 3 \\
\text { (rt-PCR tests negative, } \\
\text { but CT results } \\
\text { compatible with } \\
\text { COVID-19) }\end{array}$ & $p$-value \\
\hline Number of patients & 38 & 36 & 33 & \\
\hline Age & $49.37 \pm 15.573$ & $38.5 \pm 16.466$ & $42.61 \pm 18.469$ & $0.022^{*}$ \\
\hline Male patients & 23 & 20 & 19 & 0.910 \\
\hline Hypertension (\%) & $7(18.4)$ & $6(16.7)$ & $6(18.2)$ & 0.978 \\
\hline Diabetes mellitus (\%) & $3(7.9)$ & $4(11.1)$ & $3(9.3)$ & 0.893 \\
\hline Coronary artery disease (\%) & $2(5.3)$ & $1(2.8)$ & $1(3.0)$ & 0.827 \\
\hline Heart failure (\%) & $3(7.9)$ & $1(2.8)$ & - & 0.205 \\
\hline
\end{tabular}

Table 2. Hematology and biochemistry test results of the patients

\begin{tabular}{|c|c|c|c|c|}
\hline & $\begin{array}{l}\text { Group } 1 \\
\text { (Both CT and rt-PCR } \\
\text { results compatible with } \\
\text { COVID-19) }\end{array}$ & $\begin{array}{l}\text { Group } 2 \\
\text { (rt-PCR tests compatible } \\
\text { with COVID-19, but CT is } \\
\text { not compatible) }\end{array}$ & $\begin{array}{l}\text { Group } 3 \\
\text { (rt-PCR tests negative, } \\
\text { but CT results compatible } \\
\text { with COVID-19) }\end{array}$ & p-value \\
\hline Number of patients & 38 & 36 & 33 & - \\
\hline Hemoglobin (g/dL) & $14.11 \pm 1.894$ & $14.42 \pm 1.845$ & $14.84 \pm 2.05$ & 0.341 \\
\hline WBC (109/L) & $6.23 \pm 4.375$ & $5.98 \pm 2.284$ & $9.05 \pm 4.096$ & $0.000^{*}$ \\
\hline Urea (16-43 mg/dL) & $33.38 \pm 13.36$ & $31.93 \pm 17.251$ & $30.34 \pm 10.281$ & 0.356 \\
\hline Creatin $(0.8-13 \mathrm{mg} / \mathrm{dL})$ & $0.96 \pm 0.245$ & $0.94 \pm 0.309$ & $0.95 \pm 0.206$ & 0.544 \\
\hline ALT (0-45 U/L) & $25.76 \pm 15.079$ & $22.78 \pm 13.025$ & $25.48 \pm 20.569$ & 0.630 \\
\hline \multicolumn{5}{|c|}{$\begin{array}{l}\text { Values are mean } \pm \text { standard deviation unless stated. Normal laboratoary ranges are indicated in parentheses. A } p \text {-value }<0.05 \text { is significant, *: } p \text {-value: } 0.509 \\
\text { between group } 1 \text { and } 2 . p=0.000 \text { between group } 1 \text { and } 3 . p=0.000 \text { between group } 2 \text { and } 3,{ }^{* *}: p \text {-value: } 0.038 \text { between group } 1 \text { and } 2 . p=0.099 \text { between group } \\
1 \text { and 3. } p=0.002 \text { between group } 2 \text { and } 3 \text {. } \\
\text { ALT: Alanine aminotransferase, AST: Acetyl aminotransferase, CRP: C-reactive protein, WBC: White blood cells, CT: Computerized tomography, rt-PCR: } \\
\text { Real-time polymerase chain reaction }\end{array}$} \\
\hline
\end{tabular}


P-mins were significantly lower in group 1 than in group $3(59.32 \pm 7.353 \mathrm{~ms}$ vs $64.18 \pm 7.868 \mathrm{~ms} ; \mathrm{p}=0,009)$, and there was not significant difference between groups 1 and $2(59.32 \pm 7.353 \mathrm{~ms}$ vs $61.86 \pm 5.991 \mathrm{~ms} ; \mathrm{p}=0.108)$ and between group 2 and group $3(61.86 \pm 5.991 \mathrm{~ms}$ vs $64.18 \pm 7.868 \mathrm{~ms} ; \mathrm{p}=0.171)$. PwDs were significantly higher in group 1 compared to group 2 and group $3(53.34 \pm 7.705$ $\mathrm{ms}$ vs $40.58 \pm 4.813 \mathrm{~ms}$ and $35.42 \pm 4.116 \mathrm{~ms}$; $\mathrm{p}=0.000$ ), and significantly higher in group 2 than group $3(\mathrm{p}=0.000)$ (Figure 2). While PwPDs were significantly higher in group 1 than group 2 and group $3(56.79 \pm 7.767 \mathrm{~ms}$ vs $51.92 \pm 6.443 \mathrm{~ms}$ and $50.55 \pm 11.63 \mathrm{~ms} ; \mathrm{p}=0.008$ ), there was not significant difference between group 2 and group 3

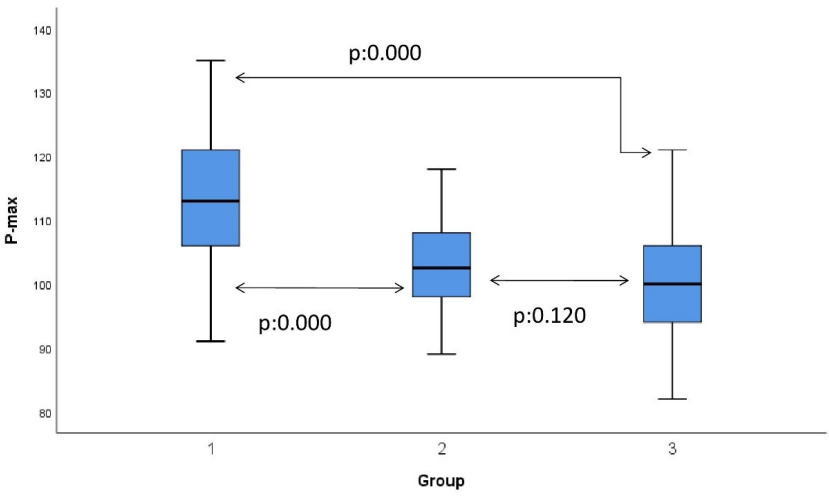

Figure 1. Analysis of patients P-max values between groups $(\mathrm{p}=0.626)$ (Figure 3$)$. The results of electrocardiographic analysis are summarized in Table 3.

\section{Discussion}

In COVID-19 infection, susceptibility to arrhythmia and thrombotic conditions have been demonstrated. The underlying pathophysiology of this condition is unclear. Alteration in P-wave durations has been shown to trigger paroxysmal atrial fibrillation. Paroxysmal atrial fibrillation and atrial arrhythmias can both increase the frequency of thrombotic events and create diastolic dysfunction. In

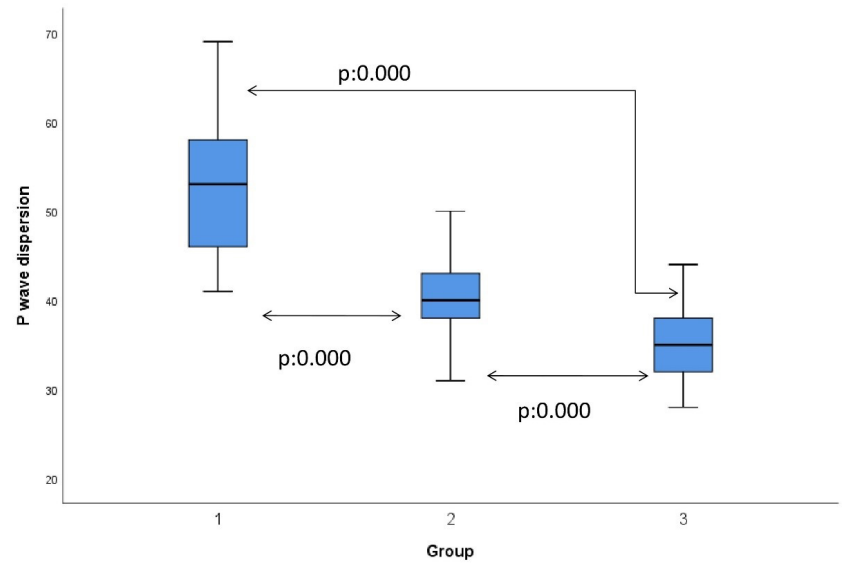

Figure 2. Analysis of patients $\mathrm{P}$-wave dispersion values between groups

Table 3. Electrocardiographic data results of patients

\begin{tabular}{|l|l|l|l|}
\hline & $\begin{array}{l}\text { Group 1 } \\
\text { (both BT and rt-PCR } \\
\text { results compatible with } \\
\text { COVID-19) }\end{array}$ & $\begin{array}{l}\text { Group 2 } \\
\text { (rt-PCR tests compatible } \\
\text { with COVID-19, but CT is } \\
\text { not compatible) }\end{array}$ & $\begin{array}{l}\text { Group 3 } \\
\text { (rt-PCR tests negative, but } \\
\text { CT results compatible with } \\
\text { COVID-19) }\end{array}$ \\
\hline p-value
\end{tabular}




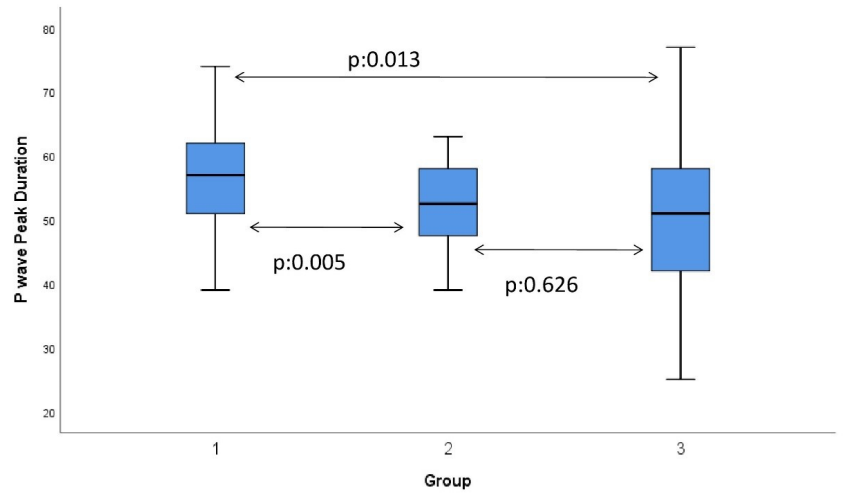

Figure 3. Analysis of patients $\mathrm{P}$-wave peak duration values between groups

this study, P-max, PwD and PwPD values were highest in patients with positive COVID-19 rt-PCR test and in those with CT compatible with COVID-19 pneumonia. $\mathrm{PwD}$ was found to be higher among patients with positive COVID-19 rt-PCR test compared to patients with negative rt-PCR test, even if there was no infiltration in the lung. In patients with positive rt-PCR test, patients demonstrating infiltration in CT had higher PwD than patients whose CT was non-compatible with COVID-19 pneumonia.

In the light of these findings, patients with positive rtPCR test and pneumonia have the longest PwD and PwPD and have highest risk for developing atrial arrhythmias. Rt-PCR positivity increases P-wave times. Based on this finding, rt-PCR positivity is one of the predictable results that may increase susceptibility to atrial arrhythmias in COVID-19 patients. We have seen in the results of this study that even if there is no pneumonic infiltration, there are more changes in the atrial conduction times in patients who have positive rt-PCR test result compared to patients with a negative test result. These results have been given rise to the thought that rt-PCR test positive patients may have an atrial or myocardial involvement with COVID-19 infection.

In addition, even if pneumonic infiltration is not shown in CT, it can be concluded that patients with proven COVID-19 infection by rt-PCR tests have increased susceptibility to atrial arrhythmias compared to patients with negative rt-PCR test results. In the light of this information, patients with pneumonia with rt-PCR positivity seem to be the group that has the highest risk of atrial tachyarrhythmia; that is why, that group may benefit most from strict ECG follow-up. Even if pneumonic infiltration is not observed in $\mathrm{CT}$, it seems that patients with rt-PCR positivity have higher atrial conduction times compared to patients with negative rt-PCR results with COVID-19 compatible infiltration.

\section{Conclusion}

In COVID-19 infected patients with rt-PCR positivity, especially in those with COVID-19 pneumonia in CT, P-max, PwD and PwPD were longer than in other patients. This difference persists in patients with $\mathrm{CT}$ negative, and as a result, it shows an increased susceptibility to atrial arrhythmias in these patients. Based on this, it is thought that strict ECG monitoring may be beneficial in PCR positive patients.

\section{Ethics}

Ethics Committee Approval: Ethical approval was taken from University of Health Sciences Turkey, Diyarbakır Gazi Yaşargil Training and Research Hospital Ethics Committee, with the report number of 509.

Informed Consent: It was obtained.

Peer-review: Externally peer-reviewed.

\section{Authorship Contributions}

Surgical and Medical Practices: B.B., E.İ., Concept: B.B., E.İ., Design: B.B., E.İ., Data Collection or Processing: B.B., E.İ., Analysis or Interpretation: B.B., E.İ., Literature Search: B.B., E.İ., Writing: B.B., E.İ.

Conflict of Interest: The authors report no conflicts of interest. The authors are the only responsible of the content which is written in this paper.

Financial Disclosure: The authors declare that this study received no financial support. 


\section{References}

1. WHO Coronavirus Disease (Covid-19) Dashboard World.18 JUNE 2020. Avaliable at: https://covid19.who.int (Accessed: 18 JUNE 2020).

2. Reddy V, Reddy V, Mangat S, Shokr M, Kundumadam S, Laharwani H. Wide complex tachycardia in a COVID-19 patient: What is the mechanism? J Electrocardiol 2020;60:200-2.

3. Kochi AN, Tagliari AP, Forleo GB, Fassini GM, Tondo C. Cardiac and arrhythmic complications in patients with COVID-19. J Cardiovasc Electrophysiol 2020;31:1003-8.

4. Beri A, Kotak K. Cardiac injury, arrhythmia, and sudden death in a COVID-19 patient. HeartRhythm Case Rep 2020;6:367-9.

5. Zhang Y, Xiao M, Zhang S, et al. Coagulopathy and Antiphospholipid Antibodies in Patients with Covid-19. N Engl J Med 2020;382:e38.

6. Gautret P, Lagier JC, Parola P, et al. Hydroxychloroquine and azithromycin as a treatment of COVID-19: results of an open-label non-randomized clinical trial. Int J Antimicrob Agents 2020;56:105949.

7. Colson P, Rolain JM, Lagier JC, Brouqui P, Raoult D. Chloroquine and hydroxychloroquine as available weapons to fight COVID-19. Int J Antimicrob Agents 2020;55:105932.

8. Turkish Ministry of Health, General Directorate of Public Health Covid-19 (SARS-CoV-2 Infection) Guidebook. 14 April 2020. Avaliable at: https:// covid19bilgi.saglik.gov.tr/depo/rehberler/COVID-19_Rehberi.pdf.

9. Kollias A, Kyriakoulis KG, Dimakakos E, Poulakou G, Stergiou GS, Syrigos K. Thromboembolic risk and anticoagulant therapy in COVID-19 patients: emerging evidence and call for action. Br J Haematol 2020;189:846-7.
10. Tang N, Bai H, Chen X, Gong J, Li D, Sun Z. Anticoagulant treatment is associated with decreased mortality in severe coronavirus disease 2019 patients with coagulopathy. J Thromb Haemost 2020;18:1094-9.

11. Rath B, Niehues P, Leitz P, Eckardt L. Vorhofflimmern bei nichtkardialen Infektionen und Sepsis [Atrial fibrillation in patients with sepsis and noncardiac infections]. Herzschrittmacherther Elektrophysiol 2019;30:256-61.

12. Kochav SM, Coromilas E, Nalbandian A, et al. Cardiac Arrhythmias in COVID-19 Infection. Circ Arrhythm Electrophysiol 2020;13:e008719.

13. Seecheran R, Narayansingh $R$, Giddings $S$, et al. Atrial Arrhythmias in a Patient Presenting With Coronavirus Disease-2019 (COVID-19) Infection. J Investig Med High Impact Case Rep 2020;8:2324709620925571.

14. Siripanthong B, Nazarian S, Muser D, et al. Recognizing COVID-19related myocarditis: The possible pathophysiology and proposed guideline for diagnosis and management. Heart Rhythm 2020;17:1463-71.

15. Yıldırım E, Günay N, Bayam E, Keskin M, Ozturkeri B, Selcuk M. Relationship between paroxysmal atrial fibrillation and a novel electrocardiographic parameter $\mathrm{P}$ wave peak time. $\mathrm{J}$ Electrocardiol 2019;57:81-86.

16. Gunduz H, Binak E, Arinc H, et al. The relationship between $\mathrm{P}$ wave dispersion and diastolic dysfunction. Tex Heart Inst J 2005;32:163-7.

17. Koide $\mathrm{Y}$, Yotsukura M, Ando H, et al. Usefulness of P-wave dispersion in standard twelve-lead electrocardiography to predict transition from paroxysmal to persistent atrial fibrillation. Am J Cardiol 2008;102:573-7.

18. Dogan A, Acar G, Gedikli O, et al. A comparison of P-wave duration and dispersion in patients with short-term and long-term atrial fibrillation. $\mathrm{J}$ Electrocardiol 2003;36:251-5. 